\title{
Parâmetros espaciais e estético-ambienais de avaliação da qualidade da arborização viária
}

\author{
Spatial and aesthetic-environmental parameters for assessing the quality of road
}

Parámetros espaciales y estético-ambientales de evaluación de la calidad de la arborización vial

Marcela Pádua Silva

Mestranda pelo PPGARQ-UNESP

marcelapaduas@hotmail.com

Maria Solange Gurgel de Castro Fontes

Doutora, PPGARQ-UNESP

sgfontes@faac.unesp.br 


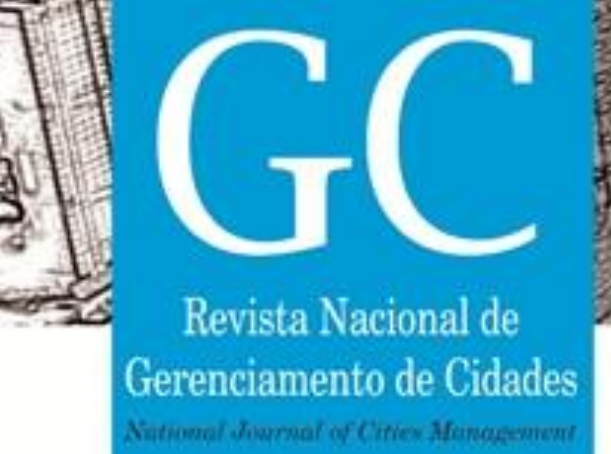

\section{RESUMO}

A arborização viária tem papel fundamental para a qualidade de vida do ambiente urbano e a avaliação da qualidade dessa infraestrutura urbana pode ser dividida em três parâmetros: espaciais, em que os índices de avaliação dizem respeito a espacialidade do indivíduo arbóreo; estético-ambiental, que contempla os indicadores relacionados à estética e benefícios ambientais do indivíduo arbóreo; e o fitossanitário, que abrange os indicadores relacionados à saúde do indivíduo arbóreo. 0 presente artigo busca apresentar e se aprofundar nos parâmetros espacial e estético-ambiental, e propõe indicadores levantados a partir de uma revisão bibliográfica focada na arborização urbana. O resultado da análise dos parâmetros e do desenvolvimento de índices evidenciam a importância da relação entre o porte do indivíduo arbóreo e sua espacialidade, e ressalta a importância da análise espacial na escolha do porte do indivíduo e também na avaliação de indivíduos arbóreos já existentes.

Palavras chave: Arborização; qualidade ambiental urbana; Infraestrutura verde.

\section{ABSTRACT}

Road planting is fundamental to the quality of life of the urban environment. The evaluation of the quality of the urban afforestation can be divided into three parameters; spatial parameters, in which the indices of evaluation refer to the spatiality of the arboreal individual; the aesthetic-environmental parameter; which includes indicators related to the aesthetics and environmental benefits of the individual tree; and the phytosanitary parameter, which includes indicators related to the health of the individual tree. The present article seeks to present and deepen the spatial and aesthetic-environmental parameters, proposing indicators based on a bibliographical review carried out on theses, dissertations, books and urban afforestation manuals. The results of the analysis of the parameters and the development of indexes show the importance of the relation between the size of the arboreal individual and its spatiality, emphasizing the importance of the spatial analysis in the choice of the individual size and also in the evaluation of already existing arboreal individuals.

Keywords: Arborization; urban environmental quality; Green infrastructure.

\section{RESUMEN}

La arborización viaria tiene un papel fundamental para la calidad de vida del ambiente urbano. La evaluación de la calidad de la arborización urbana puede dividirse en tres parámetros; los parámetros espaciales, en los que los índices de evaluación se refieren a la espacialidad del individuo arbóreo; el parámetro estético-ambiental; que contempla los indicadores relacionados a la estética y beneficios ambientales del individuo arbóreo; y el parámetro fitosanitario, que abarca los indicadores relacionados con la salud del individuo arbóreo. El presente artículo busca presentar y profundizar en los parámetros espacial y estético-ambiental, proponiendo indicadores levantados a partir de una revisión bibliográfica realizada en tesis, disertaciones, libros y manuales de arborización urbana. El resultado del análisis de los parámetros y del desarrollo de índices evidencian la importancia de la relación entre el porte del individuo arbóreo y su espacialidad, resaltando la importancia del análisis espacial en la elección del porte del individuo y también en la evaluación de individuos arbóreos ya existentes.

Palabras clave: Arborización; calidad ambiental urbana; Infraestructura verde. 


\section{INTRODUÇÃO}

A arborização viária traz inúmeros benefícios para o ambiente urbano, como a manutenção da estabilidade do microclima, o conforto térmico associado à umidade do ar e sombra (MARTINI, BIONDI E BATISTA, 2017), redução da poluição (ABBUD, 2010; MASCARÓ E MASCARÓ, 2010; MIRANDA, 1970; NUCCI E CAVALHEIRO, 1996; SOUZA, 1973) , melhoria da qualidade do ar (MASCARÓ E MASCARÓ, 2010), proteção e direcionamento dos ventos (ABBUD, 2010), melhoria da infiltração da água no solo (NUCCI E CAVALHEIRO), abrigo à fauna (MIRANDA, 1970), que contribui para o equilíbrio da cadeia alimentar, embelezamento da cidade, aumento do valor das propriedades, melhoria da saúde física e mental da população.

A discussão sobre a arborização nas cidades passa a ganhar ênfase por volta do fim dos anos 70, quando a sustentabilidade passa a ser questionada. Devido à falta de incentivo ao planejamento da arborização viária, essa importante infraestrutura verde é, muitas vezes, realizada pelos moradores. Com o crescimento rápido e desordenado das cidades, na segunda metade do século $X X$, e aumento da construção de edificações e superfícies impermeáveis, o verde urbano ficou cada vez mais reduzido.

Na maioria das cidades, o plantio de árvores nas ruas é feito de maneira desordenada e sem critérios, e isso acarreta diversos conflitos com fiação elétrica, calçadas quebradas por raízes expostas, placas de sinalização encobertas por copas, poda inadequada, entre outros.

Para auxiliar o planejamento de arborização viária existem vários manuais (BARCELLOS, 2012; PREFEITURA DE ARACRUZ, 2013; PREFEITURA DE BELÉM, 2013; PREFEITURA DE SÃO PAULO, 2013; PREFEITURA DO RIO DE JANEIRO, 2015; SECRETARIA DO MEIO AMBIENTE E SUSTENTABILIDADE DE RECIFE, 2013; PREFEITURA DE SÃO PAULO, 2015, entre outros) que indicam espécies adequadas de acordo com o local de implantação do indivíduo arbóreo. Outras referências citam métodos para avaliar um ou mais aspectos da arborização (ALVAREZ, 2012; ESTELLITA E DEMATÊ, 2007; HARDER, et al.,2006; MILANO, 1984; ROSSETTI, 2007; VIGNOLA JÚNIOR, 2015).

Porém, não há instrumento capaz de mensurar a qualidade dessa arborização já existente nas cidades, ou seja, que permita uma avaliação da sua adequabilidade e que possa auxiliar gestores na tomada de decisões mais assertivas, melhorar situações inadequadas e/ou realizar a manutenção de situações adequadas.

Nesse contexto, esta pesquisa busca suprir essa necessidade real, realizando, inicialmente, o levantamento bibliográfico com o intuito de selecionar os parâmetros e indicadores proposto por diferentes autores. Assim, a arborização viária foi analisada a partir de suas características ambientais e espaciais, como largura 


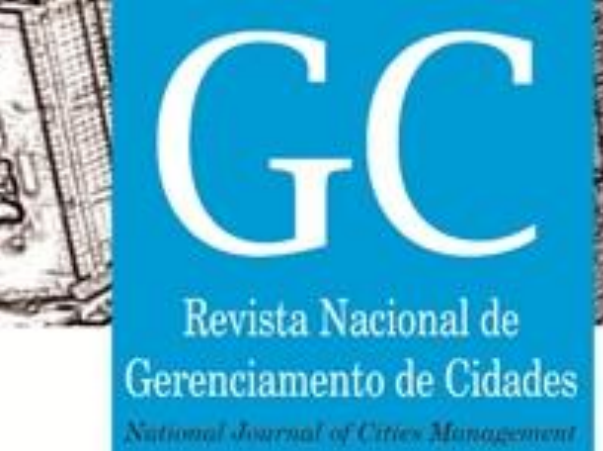

da calçada próxima, porte da árvore, altura da primeira bifurcação, distância da edificação e equipamentos urbanos, entre outros. As questões fitossanitárias, de igualmente importância, não foram estudadas nesta pesquisa.

\section{ARBORIZAÇÃO VIÁRIA}

Por definição a arborização viária é o cultivo de árvores ao longo das ruas e avenidas (SILVA, et al., 2005) e está inserida dentro da classificação de arborização urbana, que compreende o conjunto de terras públicas, semi públicas e particulares com cobertura arbórea presentes em uma cidade, de acordo com Santos (1997). Apesar da discussão sobre a arborização no perímetro urbano ter ganhando força nos último anos, ela não é umao tão recente. Sitte (1992) já comentava sobre a necessidade de se ampliar as áreas com vegetação nas cidades ao invés de tirá-las para o surgimento de novas construções.

A arborização caracteriza e qualifica o espaço urbano, seus vazios e especialmente os sistemas viários (ruas, calçadas, largos, rotatórias, praças, entre outros), segundo Abbud (2010). Ou seja, quanto mais arborizados os espaços, melhor a qualidade urbana. Os benefícios ambientais de todas as formas de arborização urbana são tão mais necessários à saúde ambiental do ecossistema urbano, quanto maior o nível de urbanização (MENEGHETTI, 2003).

Na arborização viária, as espécies arbóreas, que se encontram paralelas às vias de circulação de veículos, faz parte do cotidiano da população urbana. Ela atinge diretamente a população ao trazer conforto físico, conforto psíquico, além de contribuir para a melhoria da paisagem urbana, tornando-se referência de espaço e tempo.

A compreensão científica sobre os benefícios da vegetação urbana vem se expandindo e passa a incluir as questões sociais, ambientais e econômicas (MASCARÓ e MASCARÓ, 2010). Por isso, os interesses são os mais diversos. Em relação à arborização viária, podem-se destacar trabalhos que abordam o inventário arbóreo (PIRES, et al., 2007; NÓBREGA, et al., 2013; ROCHA, LELES e NETO, 2004; SILVA, 2012; SILVA FILHO, COSTA e POLIZEL, 2012; SANTOS, et al., 2015, MENEGHETTI, 2003; entre outros); quantidade de indivíduos por espécie (MASCARÓ e MASCARÓ, 2010; GREY e DENEKE, 1978); avaliação quali-quantitativa (MILANO, 1988; ROSSETTI, 2007, SALVI et al., 2011, BOHNER et al. 2011; ROCHA, LELES e OLIVEIRA NETO, 2004); importância para o conforto térmico (MASCARÓ,1996; BASSO E CORRÊA, 2014; CRUZ, 2013 ); indicadores de qualidade (ALVAREZ, 2004; SILVA FILHO e PIZETTA, 2002; MILANO,1988); sistematização de dados sobre arborização em programas computacionais (GERHOLD, STEINER e SACKSTEDER,1987; OLIVEIRA FILHO e 
Tabela 1. Parâmetros e indicadores identificados nos trabalhos de Milano (1984); Biondi (1985); Milano (1988); Silva Filho, et al. (2002); Meneghetti (2003).

\begin{tabular}{|c|c|c|}
\hline AUTOR & PARÂMETROS & INDICADORES \\
\hline \multirow{7}{*}{ Milano (1984) } & $\begin{array}{l}\text { Composição da arborização de } \\
\text { ruas }\end{array}$ & -Porcentagem de composição das espécies, famílias e gênero. \\
\hline & Condição das árvores & $\begin{array}{l}\text {-Condição da espécie em uma escala em que } 1 \text { apresenta uma boa } \\
\text { condição e } 4 \text { a árvore está morta ou morrendo. }\end{array}$ \\
\hline & Características das árvores & $\begin{array}{l}\text {-Tipo de Raiz; } \\
\text {-Ocorrência de pragas e doenças. }\end{array}$ \\
\hline & Tratos culturais & $\begin{array}{l}\text {-Necessidade de tratamento; } \\
\text {-Tratamentos inadequados. }\end{array}$ \\
\hline & Porte das árvores & \\
\hline & Característica dos plantios & $\begin{array}{l}\text {-Distância do meio fio; } \\
\text {-Distância das construções ou muro; } \\
\text {-Altura da fiação aérea e distância da árvore à projeção da fiação; } \\
\text {-Espaçamento ou distância da próxima árvore; } \\
\text {-Área livre; } \\
\text {-Altura de inserção do primeiro galho ou bifurcação. }\end{array}$ \\
\hline & Danos físicos na árvore & $\begin{array}{l}\text {-Identificação de danos causados por acidentes, por técnicas de } \\
\text { manejo inadequadas e por atos de vandalismo. }\end{array}$ \\
\hline \multirow[t]{3}{*}{ Biondi (1985) } & Características das árvores de rua & $\begin{array}{l}\text {-Desenvolvimento; } \\
\text {-Copa; } \\
\text {-Bifurcação; } \\
\text {-Floração e frutificação; } \\
\text {-Altura da árvore; } \\
\text {-Raízes; } \\
\text {-Resistência à poluição, pragas e doenças. }\end{array}$ \\
\hline & Características dos plantios & $\begin{array}{l}\text {-Composição de espécies; } \\
\text {-Espaçamento e posicionamento das árvores; } \\
\text {-Área de crescimento da árvore. }\end{array}$ \\
\hline & Manutenção & $\begin{array}{l}\text {-Poda; } \\
\text {-Remoção; } \\
\text {-Adubação; } \\
\text { Tratamentos fitossanitários; }\end{array}$ \\
\hline \multirow{4}{*}{ Milano (1988) } & Composição & -Porcentagem de composição das espécies, famílias e gênero. \\
\hline & Qualidade das árvores & $\begin{array}{l}\text {-Condição; } \\
\text {-Tipo de raiz; } \\
\text {-Principais problemas. }\end{array}$ \\
\hline & Característica dos plantios & $\begin{array}{l}\text {-Altura do primeiro galho ou bifurcação; } \\
\text {-Área livre; } \\
\text {-Porte das árvores; } \\
\text {-Localização; } \\
\text {-Espaçamento entre árvores; } \\
\text {-Relação "porte x espaço" }\end{array}$ \\
\hline & Necessidade de manejo & \\
\hline $\begin{array}{l}\text { Silva Filho, et al. } \\
\qquad(2002)\end{array}$ & Localização e identificação & $\begin{array}{l}\text {-Nome da rua; } \\
\text {-Número do imóvel onde se encontra a árvore; } \\
\text {-Bairro; }\end{array}$ \\
\hline
\end{tabular}




\begin{tabular}{|c|c|c|}
\hline & & $\begin{array}{l}\text {-Espécie; } \\
\text {-Largura da rua; } \\
\text {-Largura da calçada. }\end{array}$ \\
\hline & Dimensões & $\begin{array}{l}\text {-Altura total; } \\
\text {-Altura da primeira bifurcação; } \\
\text {-Diâmetro da copa; } \\
\text {-Perímetro à altura do peito. }\end{array}$ \\
\hline & Biologia & $\begin{array}{l}\text { - Estado geral- Condição da árvore (Ótimo, Bom, Regular e Péssimo); } \\
\text { - Equilíbrio geral; } \\
\text { - Fitossanidade; } \\
\text { - Intensidade (de fitossanidade); } \\
\text {-Local de ataque; } \\
\text {-Injúrias. }\end{array}$ \\
\hline & Entorno e interferências & $\begin{array}{l}\text {-Localização relativa; } \\
\text {-Tráfego; } \\
\text {-Participação na paisagem; } \\
\text {-Situação adequada; }\end{array}$ \\
\hline & Definição de ações & $\begin{array}{l}\text {-Quando é observada alguma atividade de poda, sendo classificada } \\
\text { como Ótima, Boa, Regular ou Péssima. }\end{array}$ \\
\hline \multirow{6}{*}{$\begin{array}{l}\text { Meneghetti } \\
\text { (2003) }\end{array}$} & Quadra & $\begin{array}{l}\text {-Estrato e no do quarteirão; } \\
\text {-Nome da rua; } \\
\text {-Largura da rua; } \\
\text {-Tipo de ocupação de cada quadra; } \\
\text {-Largura da calçada; } \\
\text {-Afastamento predial. }\end{array}$ \\
\hline & $\begin{array}{l}\text { Espécie e localização do } \\
\text { indivíduo }\end{array}$ & $\begin{array}{l}\text {-no da quadra; } \\
\text {-no da árvore; } \\
\text {-Espécie. }\end{array}$ \\
\hline & Tamanho do indivíduo & $\begin{array}{l}\text {-Altura total; } \\
\text {-Circunferência a altura do peito. }\end{array}$ \\
\hline & Conduta da planta & $\begin{array}{l}\text {-Altura da primeira bifurcação; } \\
\text {-Tipo de poda. }\end{array}$ \\
\hline & Saúde da Planta & $\begin{array}{l}\text {-Qualidade da copa; } \\
\text {-Qualidade do tronco; } \\
\text {-Inclinação do tronco; } \\
\text {-Fitossanidade. }\end{array}$ \\
\hline & Local de Plantio & $\begin{array}{l}\text {-Adequação da espécie ao local; } \\
\text {-Área livre de pavimentação; } \\
\text {-Condição da calçada; } \\
\text {-Obstáculos existentes; } \\
\text {-Fiação existente. }\end{array}$ \\
\hline
\end{tabular}

Essas divisões podem ser identificadas em grupos mais amplos, como o exemplo citado por Milano (1987), que divide seus parâmetros em: Características ambientais, Características de espécie e Características do espaço físico. Assim criou-se os parâmetros Espaciais, Estético-ambientais e Fitossanitários. 


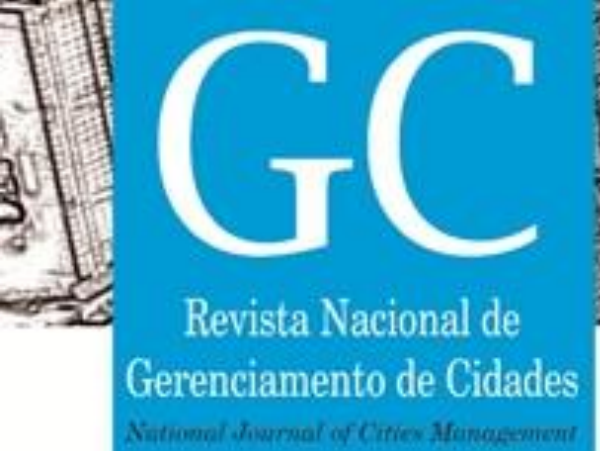

ISSN 2318-8472

Para os parâmetros Espaciais os indicadores devem mensurar a qualidade espacial da arborização, tais como medidas, distâncias, áreas. Para os parâmetros Estético-ambientais, os indicadores devem possuir valor paisagístico, de diversidade de espécies, que influenciam a estética e possuem influência na climatização do local em que o indivíduo arbóreo está inserido. Já para os parâmetros Fitossanitários, os indicadores devem designar a saúde do indivíduo arbóreo, qualidade da poda, ou presença de doenças.

\subsection{Parâmetros espaciais}

O parâmetro espacial incorpora os indicadores que dizem respeito à espacialidade do indivíduo, como: largura da calçada; afastamento predial; área livre de pavimentação; condição da calçada; obstáculos existentes; distância da árvore até o meio fio; espaçamento até a próxima árvore; análise do tipo de fiação existente; distância da árvore em relação à infraestrutura. A tabela 2 apresenta os indicadores selecionados para compor este parâmetro, assim como os autores que citam cada indicador e como cada autor mensura o mesmo.

A espacialidade do indivíduo arbóreo possui relação direta com a qualidade do ambiente urbano, e ao trabalho do arquiteto urbanista, sendo importante seu estudo e aprofundamento. 


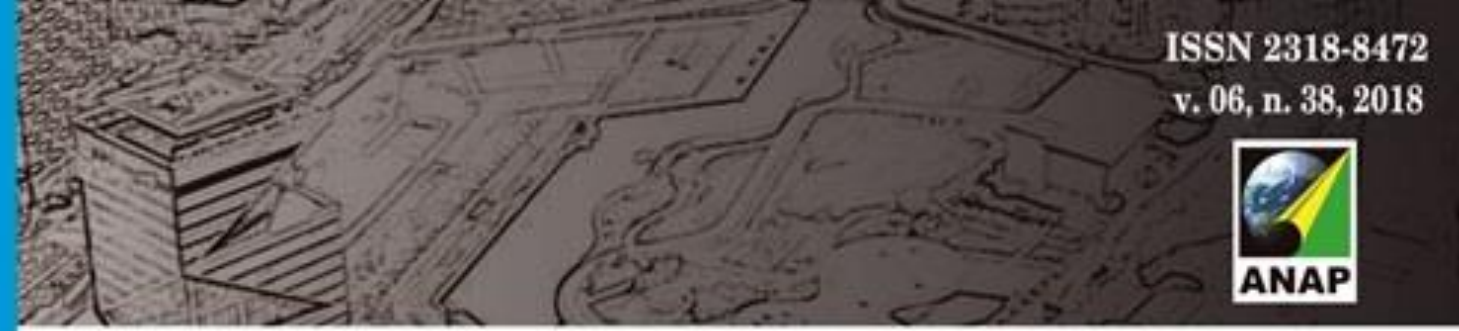

Gerenciamento de Cidades

Tabela 2. Indicadores para o parâmetro espacial de avaliação da qualidade da arborização viária

\begin{tabular}{|c|c|c|}
\hline INDICADORES & AUTORES & ANÁLISE POR AUTOR \\
\hline \multirow[t]{2}{*}{ Largura da calçada } & Meneghetti (2003) & $\begin{array}{l}\text { Não indica um tamanho ideal. Divide a classificação de calçadas da } \\
\text { seguinta maneira: menor ou igual a } 1 \mathrm{~m} \text {; de } 1,1 \text { à } 2 \mathrm{~m} \text {; de } 2,1 \text { à } 3 \mathrm{~m} \text {; de } 3,1 \\
\text { à } 4 \mathrm{~m} \text { e maior que } 4 \mathrm{~m} \text {. Sendo em sua área de análise a maior parte das } \\
\text { calçadas }(42,6 \%) \text { se enquadra na faixa de } 2,1 \text { à } 3,0 \mathrm{~m} \text {. }\end{array}$ \\
\hline & $\begin{array}{l}\text { Silva Filho, et al. } \\
(2002)\end{array}$ & Não indica um tamanho ideal. Computa, mas não analisa a informação. \\
\hline \multirow[t]{2}{*}{ Largura da Rua } & Meneghetti (2003) & $\begin{array}{l}\text { Não indica um tamanho ideal. Divide a classificação de ruas da seguinta } \\
\text { maneira: de } 5,5 \text { à } 7,5 \mathrm{~m} \text {; de } 7,6 \text { à } 9,5 \mathrm{~m} \text {; De } 9,6 \text { à } 11,5 \mathrm{~m} \text {; maior que } 11,5 \mathrm{~m} \text {. } \\
\text { Sendo em sua área de análise a maior parte das ruas }(38,3 \%) \text { se } \\
\text { enquadra na faixa de } 5,5 \text { à } 7,5 \mathrm{~m} \text {. }\end{array}$ \\
\hline & $\begin{array}{l}\text { Silva Filho, et al. } \\
\text { (2002) }\end{array}$ & Não indica um tamanho ideal. Computa, mas não analisa a informação. \\
\hline \multirow{5}{*}{$\begin{array}{l}\text { Afastamento predial } \\
\text { (distância das construções ou } \\
\text { muros) }\end{array}$} & Meneghetti (2003); & $\begin{array}{l}\text { Não indica um tamanho ideal. Divide a classificação de afastamento da } \\
\text { seguinta maneira: sem afastamento; de } 1 \text { à } 2,5 \mathrm{~m} \text {; entre } 2,5 \text { e } 4 \mathrm{~m} \text { e maior } \\
\text { que } 4 \mathrm{~m} \text {. Sendo em sua área de análise a maior parte dos afastamentos } \\
(66,7 \%) \text { se enquadra na faixa de } 2,5 \mathrm{~m} \text {. }\end{array}$ \\
\hline & Milano (1984); & $\begin{array}{l}\text { Não indica um tamanho ideal. Apresenta que sua área de análise possui } \\
\text { média de afastamento de } 3,5 \mathrm{~m} \text {. O autor indica que não encontrou na } \\
\text { literatura a informação. }\end{array}$ \\
\hline & Biondi (1985); & $\begin{array}{l}\text { Não indica um tamanho ideal. Apresenta que sua área de análise possui } \\
\text { média de afastamento de } 2,0 \mathrm{~m} .0 \text { autor indica que não encontrou na } \\
\text { literatura a informação. }\end{array}$ \\
\hline & Milano (1988); & $\begin{array}{l}\text { Não indica um tamanho ideal. Apresenta que sua área de análise possui } \\
\text { média de afastamento de } 2,7 \mathrm{~m} \text { e compara com outros autores. }\end{array}$ \\
\hline & $\begin{array}{l}\text { Silva Filho, et al. } \\
\text { (2002). }\end{array}$ & $\begin{array}{l}\text { Não realiza medições exatas, apenas analisa a posição da árvore em } \\
\text { relação à construção: } \\
\text { Junto à guia - quando a árvore está localizada próximo } \\
\text { da guia da calçada. } \\
\text { Centrada - quando a árvore está localizada no centro da calçada. } \\
\text { Junto à divisa - quando a árvore está localizada } \\
\text { próximo do muro ou da cerca do imóvel. }\end{array}$ \\
\hline \multirow[t]{4}{*}{ Àrea livre de pavimentação } & Milano (1984); & $\begin{array}{l}\text { Toma como base o trabalho de Wyman (1972), realizado nos Estados } \\
\text { Unidos da América, que considera a área livre ideal de aproximadamente } \\
6 \mathrm{~m}^{2} \text {. Milano obtem o resultado médio de } 5,67 \mathrm{~m}^{2} \text { em Curitiba. }\end{array}$ \\
\hline & Biondi (1985). & $\begin{array}{l}\text { Toma como base o trabalho de Wyman (1972), realizado nos Estados } \\
\text { Unidos da América, que considera á área livre ideal de aproximadamente } \\
6 \mathrm{~m}^{2} \text {. Encontra o valor médio de } 1,23 \mathrm{~m}^{2} \text { para a área analisada. }\end{array}$ \\
\hline & Milano (1988); & $\begin{array}{l}\text { O autor encontra um resultado de } 3,7 \mathrm{~m}^{2} \text { de área livre. Realiza } \\
\text { comparação com Milano (1984) e Biondi (1985). E toma como base a } \\
\text { medida ideal de } 6 \mathrm{~m}^{2} \text { indicada por Wyman (1972). }\end{array}$ \\
\hline & Meneghetti (2003); & $\begin{array}{l}\text { Autora não cita como realiza numericamente a divisão, mas classifica as } \\
\text { áreas como: Adequadas, pequenas e ausentes (quando a área livre é } \\
\text { toda ocupada por raízes ou cimentada). Em seu estudo } 51 \% \text { dos casos a } \\
\text { área livre de pavimentação foi considerada pequena. }\end{array}$ \\
\hline Condição da calçada & Meneghetti (2003). & $\begin{array}{l}\text { Não explica o que é levado em conta para a classificação da condição da } \\
\text { calçada. Classifica em : Danos severos ( } 19,8 \% \text { dos casos da área } \\
\text { estudada); Danos leves ( } 29,41 \% \text { dos casos da área estudada) e Bom } \\
\text { estado ( } 50,78 \% \text { dos cados da área estudada). }\end{array}$ \\
\hline Obstáculos existentes & Meneghetti (2003). & $\begin{array}{l}\text { Incluia a presença de elementos construídos que pudessem impedir ou } \\
\text { dificultar o desenvolvimento das raízes, do tronco ou da copa, ou ainda o } \\
\text { aumento da área livre de pavimentação. Entre o obstáculos analisados } \\
\text { estão: poste; garagem; canalização; bueiro; estacionamento comercial; } \\
\text { esquina; placa de trânsito; placa comercial; marquise; entulho; obra; } \\
\text { lixeira; banca de jornal ou frutas; toldo; ponto de ônibus; canalização de }\end{array}$ \\
\hline
\end{tabular}




\begin{tabular}{|c|c|c|}
\hline & & gás de cozinha; semáforo e varanda. \\
\hline \multirow[t]{2}{*}{$\begin{array}{l}\text { Distância da árvore até o } \\
\text { meio fio }\end{array}$} & Milano (1984); & $\begin{array}{l}\text { Segue como base a recomendação de uma distância mínima de } 1 \mathrm{~m} . \\
\text { Encontrou em sua pesquisa a distância média de 1,56m em Curitiba- PR. }\end{array}$ \\
\hline & Biondi (1985); & $\begin{array}{l}\text { Autora compara o resultado com a indicação feita por Santiago (1980), } \\
\text { que sugere a distância ideal de } 30 \text { a } 40 \mathrm{~cm} \text { e a recomendação do PLANO } \\
\text { DE ARBORIZAÇÃO URBANA DE CURITIBA, que recomenda a distância de } \\
1 \mathrm{~m} \text {. }\end{array}$ \\
\hline \multirow[t]{2}{*}{$\begin{array}{l}\text { Distância do tronco da árvore } \\
\text { à projeção da fiação aérea }\end{array}$} & Milano (1984); & $\begin{array}{l}\text { Não indica uma distância ideal. Aponta que deve ser considerado junto a } \\
\text { essa informação, o porte da árvore. Obtêm o valor médio de } 1,2 \mathrm{~m} \text { de } \\
\text { distância entre árvore e fiação. Conclui que espécies de grande porte } \\
\text { sejam plantadas em ruas que tenham a fiação baixa e mantidas com } \\
\text { podas de condução. Já árvores de pequeno porte sejam plantadas sob } \\
\text { fiação alta, para diminuir a necessidade de podas. }\end{array}$ \\
\hline & Biondi (1985). & $\begin{array}{l}\text { Não indica uma distância ideal. Aponta que deve ser considerado junto a } \\
\text { essa informação, o porte da árvore. Obtêm o valor médio de } 4,42 \mathrm{~m} \text { de } \\
\text { distância entre árvore e fiação. }\end{array}$ \\
\hline \multirow[t]{3}{*}{$\begin{array}{l}\text { Espaçamento até a próxima } \\
\text { árvore }\end{array}$} & Milano (1984); & $\begin{array}{l}\text { Autor usa como referência Wyman (1972) que indica espaçãmento de } 10 \\
\text { metros para árvores de pequeno porte, e } 22 \mathrm{~m} \text { entre árvores de grande } \\
\text { porte. O autor obtem em seu estudo uma média de } 11,3 \mathrm{~m} \text { de distância } \\
\text { entre as árvores e reforça a necessidade de analisar tal informação em } \\
\text { conjunto com o porte do indivíduo arbóreo. }\end{array}$ \\
\hline & Milano (1988); & $\begin{array}{l}\text { Autor usa como referência Wyman (1972) que indica espaçamento de } 10 \\
\text { metros para árvores de pequeno porte, e } 22 \mathrm{~m} \text { entre árvores de grande } \\
\text { porte. O autor obtem em seu estudo uma média de } 11,6 \mathrm{~m} \text { de distância } \\
\text { entre as árvores e reforça a necessidade de analisar tal informação em } \\
\text { conjunto com o porte do indivíduo arbóreo. Autor compara seu resultado } \\
\text { com Milano (1984) e Biondi ( 1985). }\end{array}$ \\
\hline & Biondi (1985); & $\begin{array}{l}\text { Porte pequeno- } 9 \mathrm{~m} \text { de distância; Porte médio- } 12 \mathrm{~m} \text { de distância; Porte } \\
\text { Grande-12 m de distância. Espaçamento médio obtido na pesquisa: } \\
12,23 \mathrm{~m} \text {. }\end{array}$ \\
\hline $\begin{array}{l}\text { Distância das árvores em } \\
\text { relação à infraestrutura }\end{array}$ & $\begin{array}{l}\text { Silva Filho, et al. } \\
\text { (2002). }\end{array}$ & $\begin{array}{l}\text { Atual - quando o equipamento urbano ou edificação está em contato } \\
\text { com alguma parte da árvore. } \\
\text { Potencial - quando a espécie, pelo seu crescimento normal, vai entrar } \\
\text { em contato com algum equipamento ou edificação. } \\
\text { Ausente - quando não existir possibilidade de } \\
\text { contato. }\end{array}$ \\
\hline \multirow[t]{5}{*}{ Nome da via } & Meneghetti (2003); & \multirow[t]{5}{*}{ Todos os autores citam o nome da via. } \\
\hline & Milano (1984); & \\
\hline & Biondi (1985); & \\
\hline & $\begin{array}{l}\text { Silva Filho, et al. } \\
\text { (2002); }\end{array}$ & \\
\hline & Meneghetti (2003). & \\
\hline \multirow{3}{*}{$\begin{array}{l}\text { № do quarteirão ao qual o } \\
\text { indivíduo pertence }\end{array}$} & Meneghetti (2003); & \multirow[t]{3}{*}{ Todos os autores citam o no do quarteirão ao qual o indivíduo pertence, } \\
\hline & Milano (1988); & \\
\hline & $\begin{array}{l}\text { Silva Filho, et al. } \\
\text { (2002). }\end{array}$ & \\
\hline Cabos de fiação existentes & Meneghetti (2003); & $\begin{array}{l}\text { Tipos de fiação existentes: Telefônica; Secundária; Primária; Pré-reunida; } \\
\text { Condutor de tróleibus ou alimentador de tróleibus. }\end{array}$ \\
\hline \multirow[t]{3}{*}{ Nome do Bairro } & Biondi (1985). & \multirow[t]{3}{*}{ Nome do bairro em que o indivíduo arbóreo está inserido. } \\
\hline & Meneghetti (2003); & \\
\hline & $\begin{array}{l}\text { Silva Filho, et al. } \\
\text { (2002). }\end{array}$ & \\
\hline
\end{tabular}




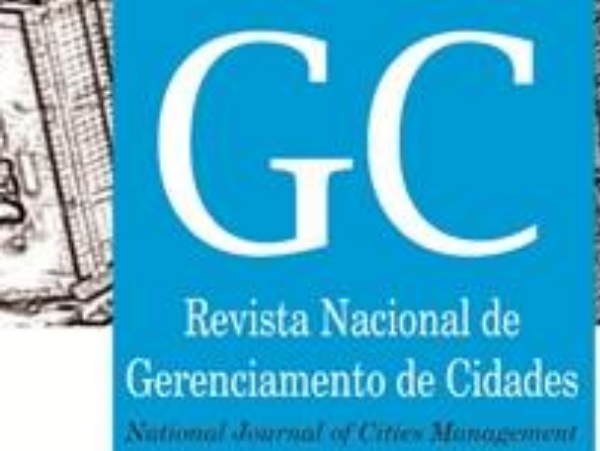

Entre os indicadores apresentados para o parâmetro espacial, observa-se a distribuição em 2 grupos característicos, que podem ser separados em: os indicadores cadastrais, e os indicadores de características espaciais do entorno, que buscam as informações de relação da árvore com elementos do seu entorno.

A figura 01 apresenta o esquema de classificação para o parâmetro espacial.

Figura 1. Classificação Parâmetro espacial

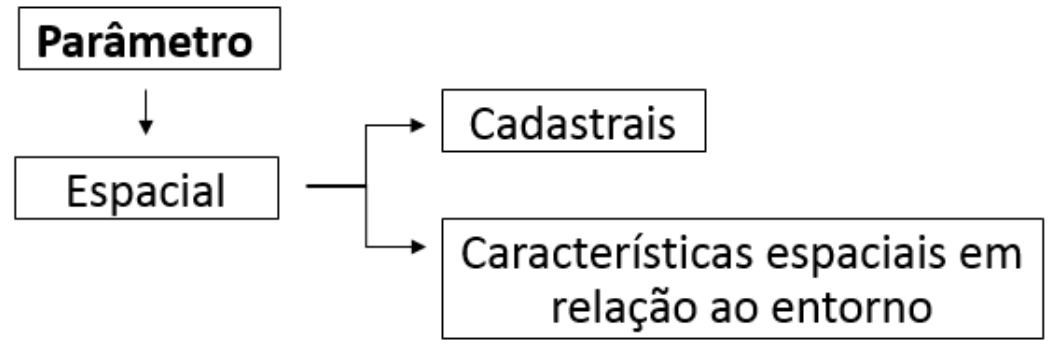

FONTE: a autora

Os indicadores cadastrais possuem a função de auxiliar na localização do indivíduo arbóreo, tais como:

-Nome da via: Nome da rua, avenida, ou via que passa paralela ao indivíduo arbóreo analisado.

-Número do quarteirão ao qual o indivíduo pertence: Número oficial do quarteirão, cadastrado na prefeitura, ao qual a árvore pertence.

-Nome do bairro: Nome do bairro em que o indivíduo analisado pertence.

Os indicadores de características espaciais do entorno em relação à árvore constituem as medidas do próprio indivíduo arbóreo analisado, e são assim denominados:

- Largura da calçada: distância do limite do lote ao qual a árvore pertence até o meio fio.

- Largura da via: distância do meio fio ao meio fio paralelo da via cuja qual a árvore faz parte.

-Afastamento predial: o afastamento predial diz respeito ao recuo frontal da edificação com o limite frontal do terreno. Nesse índice é analisado a presença ou não do recuo.

-Área livre de pavimentação: Canteiro ou espaço destinado para o crescimento do indivíduo arbóreo, que não haja a presença de material impermeável, ou que obstrua a infiltração natural das águas da chuva no solo.

- Condição da calçada: situação em que se encontra a calçada próxima ao indivíduo arbóreo, contabilizando-se a área da projeção de sua copa. As calçadas podem ser ter as seguintes características: 1 . Em bom estado: poucas rachaduras com fissuras de tamanho inferior à $2 \mathrm{~mm}$, nenhum levantamento de piso; 2. Danos leves: pequenas rachaduras, levantamento leve de piso e raiz pouco exposta; 3 . Danos 


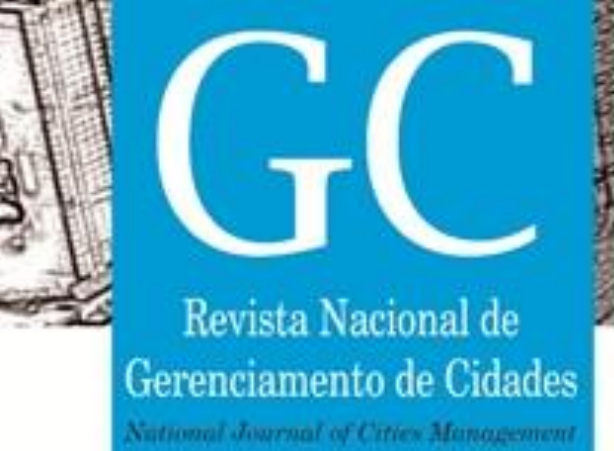

Tabela 3. Indicadores para o parâmetro estético-ambiental de avaliação da qualidade da arborização viária

\begin{tabular}{|c|c|c|}
\hline INDICADORES & AUTORES & ANÁLISE POR AUTOR \\
\hline \multirow{4}{*}{ Espécies (composição) } & Milano (1984) & $\begin{array}{l}\text { Autor cita a recomendação de Grey e Deneke (1978), de que cada } \\
\text { espécie utilizada não atinja mais que } 10 \text { ou } 15 \% \text { da população total. O } \\
\text { autor obteve como resultado de seu estudo } 18 \text { espécies diferentes, } \\
\text { porém a espécie mais encontrada representa } 24 \% \text { dos indivíduos das } \\
\text { área amostrada, e a segunda espécie mais recorrente apresenta } 14,7 \% \\
\text { da quantidade total. O autor considerou como um alto risco de } \\
\text { contaminação. }\end{array}$ \\
\hline & Biondi (1985) & $\begin{array}{l}\text { A autora discorre sobre o valor paisagístico da composição arbórea e } \\
\text { também cita a referência de Grey e Deneke (1978). Foi encontrado na } \\
\text { área estudada } 31 \text { espécies diferentes. A árvore mais frequente } \\
\text { representava } 36,9 \% \text { do total analisado. A segunda árvore mais comum } \\
\text { representava } 16,6 \% \text {. }\end{array}$ \\
\hline & Milano (1988) & $\begin{array}{l}\text { Autor novamente toma como referência Grey e Deneke (1978). Encontro- } \\
\text { se na área estudada mais de } 75 \text { espécies, sendo a maior parte das } \\
\text { espécies feitas por plantio irregular. } 96 \% \text { da população das árvores } \\
\text { analisadas eram representadas por } 15 \text { espécies, com frequencia relativa } \\
\text { variável. A espécie mais plantada compreende } 49,83 \% \text { do total de } \\
\text { indivíduos analisados. }\end{array}$ \\
\hline & Meneghetti & $\begin{array}{l}\text { A autora encontrou no Estrato ponta da Praia foram encontradas } 33 \\
\text { espécies, sendo que a espécie mais recorrente representa } 31 \% \text { do total } \\
\text { de indivíduos. No Embaré foram encontradas } 26 \text { espécies, sendo que a } \\
\text { espécie mais recorrente representa } 38,4 \% \text { do total de indivíduos. No } \\
\text { Estrato Composto foram encontradas } 24 \text { espécies, sendo que a espécie } \\
\text { mais recorrente representa } 32 \% \text { do total de indivíduos. No Estrato } \\
\text { Boqueirão foram encontradas } 31 \text { espécies, sendo que a espécie mais } \\
\text { recorrente representa } 28,6 \text { do total de indivíduos. No Estrato Aparecida } \\
\text { foram encontradas } 31 \text { espécies, sendo que a espécie mais recorrente } \\
\text { representa } 22,6 \% \text { do total de indivíduos. }\end{array}$ \\
\hline \multirow[t]{4}{*}{$\begin{array}{l}\text { Altura da primeira } \\
\text { bifurcação }\end{array}$} & Milano (1984) & $\begin{array}{l}\text { O autor encontrou a altura média de } 1,8 \mathrm{~m} \text {, com desvio padrão de } 0,95 \mathrm{~m} \text {. } \\
\text { Autor cita Miranda (1970), que indica no mínimo } 2,0 \mathrm{~m} \text { para altura da } \\
\text { primeira bifurcação. }\end{array}$ \\
\hline & Biondi (1985) & $\begin{array}{l}\text { Cita Webster (1972) e São Paulo (1974) que indicam que as árvores } \\
\text { deverão ter tronco livre de ramificação até a altura de } 1,80 \mathrm{~m} \text {. Autora } \\
\text { encontrou na área analisada uma altura média de } 2,20 \mathrm{~m} \text {, com desvio } \\
\text { padrão de } 0,87 \mathrm{~m} \text {. }\end{array}$ \\
\hline & Milano (1988) & $\begin{array}{l}\text { Foi encontrado uma altura média de } 1,8 \mathrm{~m} \text { na amostra analisada e um } \\
\text { desvio padrão de } 0,6 \mathrm{~m} \text {. }\end{array}$ \\
\hline & Meneghetti (2003) & Obteve uma média de 2,42 m. \\
\hline \multirow[t]{3}{*}{$\begin{array}{l}\text { Condição do sistema } \\
\text { radicular }\end{array}$} & Milano (1984) & $\begin{array}{l}\text { O autor cita Miranda (1970), Souza (1973) e Santiago (1970) que } \\
\text { recomendam a utilização de espécies com raízes de profundidade para a } \\
\text { arborização de ruas. Autor classificou as árvores encontradas pontuando } \\
\text { da seguinte maneira: } 1 \text { (raiz superficial); } 3 \text { (raiz de profundidade). Obteve } \\
\text { uma média de 2,8, que indica a predominância de espécies com raízes } \\
\text { profundas. }\end{array}$ \\
\hline & Biondi (1985) & $\begin{array}{l}\text { Autora cita Miranda (1970), Souza (1973) e Santiago (1970), que } \\
\text { recomendam a utilização de espécies com raízes pivotantes para a } \\
\text { arborização viária. Autora pontua as árvores analisadas da seguinte } \\
\text { maneira: } 1 \text { (boa) ; } 2 \text { (regular); } 3 \text { (ruim). Como resultado obteve-se a } \\
\text { pontuação 1,9, indicando que a maior parte das árvores analisadas } \\
\text { encontram-se em situação de boa a regular. }\end{array}$ \\
\hline & Milano (1988) & $\begin{array}{l}\text { Autor utiliza a escala de } 1 \text { a } 3 \text {, em que } 1 \text { representa raízes de } \\
\text { profundidade e } 3 \text { representa raízes superficiais. Foi obtida uma média de } \\
1,2 \text {, indicando que } 85,1 \% \text { das árvores da área analisada possuiam raízes } \\
\text { profundas. }\end{array}$ \\
\hline
\end{tabular}




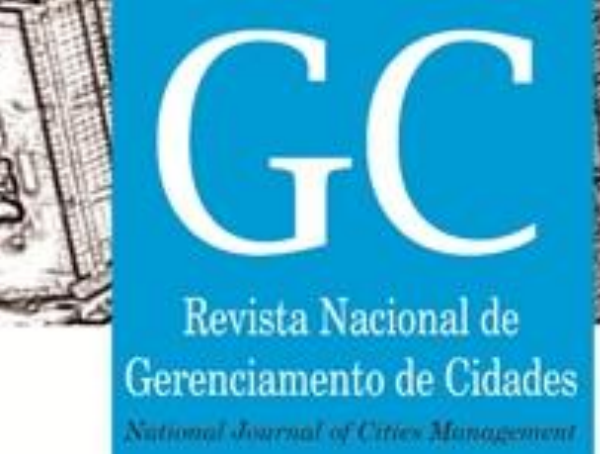

\section{CONCLUSÃO}

Mesmo com uma variedade de trabalhos sobre a arborização viária, verifica-se uma falta de padronização de parâmetros e indicadores utilizados para a qualificação da arborização viária, o que dificulta a comparação e análise de diferentes resultados. Assim, este trabalho buscou sistematizar e classificar os indicadores para o parâmetro espacial e estético-ambiental.

O indicador "altura total da árvore" apareceu em todas as referências para a qualificação da arborização viária, associada a vários outros indicadores, que possuem relação direta com o mesmo. O que sugere que o porte da árvore irá influenciar na qualidade de sua relação com o entorno.

O estudo e padronização de parâmetros permitem o desenvolvimento de estudos comparativos em diferentes locais. Assim, pode haver um padrão de comparação e também possível analisar pontos em que podem ser melhorados em cada área de estudo.

Ressalta-se aqui que, o estudo aprofundado da relação do indivíduo arbóreo e sua espacialidade possui relação estreita com a função do arquiteto urbanista. Sua exploração e sistematização trarão inúmeros benefícios ao que diz respeito ao planejamento e adequação da arborização viária, e pode contribuir para uma maior qualidade de vida às cidades.

\section{REFERÊNCIAS}

ABBUD, B. Criando Paisagens: Guia de trabalho em arquitetura paisagística. 4⿳a.. ed. São Paulo: SENAC, 2010.

ALVAREZ, I. A. Qualidade do espaço verde urbano: Uma proposta de índice de Avaliação. Escola Superior "Luiz de Quairoz"- Universidade de São paulo. Piracicaba, p. 187. 2004.

BARCELLOS, A. et al. Manual de elaboração do plano municipal de arborização Urbana-PR. [S.I.]. 2012.

BASSO, J. M.; CORRÊA, R. S. Arborização urbana e qualificação da paisagem. Paisagem e Ambiente, São Paulo, v. 34, p. 129-148, 2014.

BIONDI, D. Diagnóstico da arborização de ruas da cidade de Recife. Universidade Federal do Paraná. Curitiba, p. 188. 1985.

BOBROWSKI, R.; BIONDI, D. Morfometria de espécies florestais plantadas nas calçadas. REVSBAU, Piracicaba, v. $12, \mathrm{n}$. 1, p. 01-16, 2017. ISSN 1980-7694.

BOHNER, T. et al. Análise quali-quantitativa da arborização do município de Guatambu. REMOA, v. 3, n. 3, p. 532-546, 2011. 


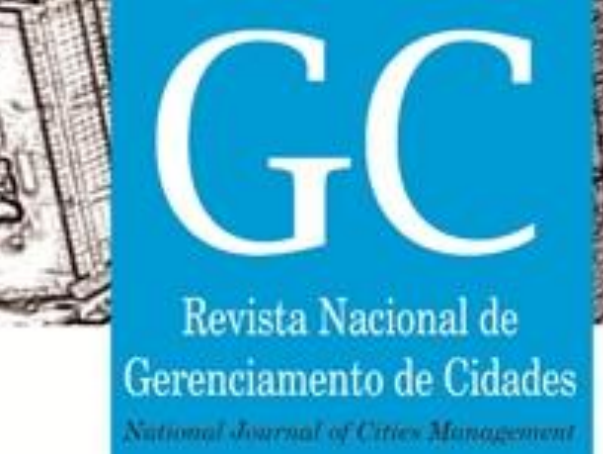

CRUZ, B. M. Procedimentos metodológicos para avaliação da arborização urbana na cidade de São Paulo. Paisagem e Ambiente, São Paulo, n. 31, p. 25-60, 2013.

ESTELLITA, M.; DEMATTÊ, M. E. S. P. Índice de valor Paisagístico para árvores em ambiente urbano. Revista Brasileira de Horticultura Ornamental, v. 12, n. 2, p. 103-111, 2007.

GERHOLD, H. D.; STEINER, K. C.; SACKSTEDER, C. J. Management Information Systems for urban trees. Journal of arboriculture, v. 13, p. 243-249, Outubro 1987.

GREY, G. M.; DENEKE, F. J. Urban Forestry. Nova lorque: John Miley, 1978. 279 p.

HARDER, I. C. F.; RIBEIRO, R. C. S.; TAVARES, A. R. Índices de área verde e cobertura vegetal para as praças do município de Vinhedo-SP. Revista Árvore, Viçosa, v. 30, n. 2, p. 277-282, 2006.

LANDGRAF, P. R. C.; PAIVA, P. D. O.; REIS, L. A. Desenvolvimento de software para o planejamento da arborização urbana. Revista Brasileira de Horticultura Ornamental, v. 19, n. 1, p. 19-24, 2013.

MARTINI, A.; BIONDI, D.; BATISTA, A. C. Influência das diferentes tipologias metereológicas de floresta urbana na atenuação dos extremos metereológicos. Advances in Forestry Science, Cuiabá, v. 4, n. 3, p. 125-129, Setembro 2017.

MASCARÓ, L. Ambiência Urbana. Porto Alegre: Ed. Sangra, 1996.

MASCARÓ, L.; MASCARÓ, J. L. Vegetação Urbana. 3ạ. ed. Porto Alegre: +4 Editora, 2010.

MENEGHETTI, G. I. P. Estudo de dois métodos de amostragem para Inventário da Arborização de ruas dos bairros da Orla marítima do município de Santos,SP. Escola Superior Agrícola "Luiz de Queiroz", Universidade de São Paulo. Piracicaba, p. 98. 2003.

MILANO, M. S. Avaliação e análise da arborização das ruas de Curitiba. Universidade Federal do Paraná. Curitiba, p. 130. 1984.

MILANO, M. S. Avaliação Quali-Quantitativa e manejo da arborização urbana: exemplo de Maringá-PR. Universidade Federal do Paraná. Curitiba, p. 120. 1988.

MIRANDA, M. A. D. L. Arborização de vias públicas. Secretaria da Agricultura de São Paulo. Campinas, p. 49.1970.

NUCCI, J. C.; CAVALHEIRO, F. Cobertura vegetal em áreas urbanas- Conceito e métodos. GEOUSP, n. 6, p. 29-36, 1996.

OLIVEIRA FILHO, P. C.; SILVA, S. V. K. Um sistema de informações para suporte espacial e de decisões à gestão da arborização urbana no município de Guarapuava, Paraná. REVSBAU, Piracicaba, v. 5, n. 3, p. 82-96, 2010.

PIRES, N. M. T. et al. Diagnóstico da arborização urbana do município de Goiandira, Goiás. Revista Brasileira de Biociências, Porto Alegre, v. 5, p. 537-539, julho 2007.

PREFEITURA DA CIDADE DE SÃO PAULO. Manual de arborização 2a edição. Manual de arborização, 2005. Disponivel em: <http://www.prefeitura.sp.gov.br/cidade/secretarias/upload/manual_arborizacao_1253202256.pdf>. Acesso em: 05 fev. 2017.

PREFEITURA DE ARACRUZ. Manual de recomendações técnicas para projetos de arborização urbana e procedimento de poda. Secretaria Municipal do Meio Ambiente. Aracruz, p. 34. 2013.

PREFEITURA DE BELÉM. Manual de orientação técnica urbana de Belém. Prefeitura de Belém. [S.I.]. 2013.

PREFEITURA DO RIO DE JANEIRO. Plano diretor de arborização Urbana da Cidade do Rio de Janeiro. Prefeitura do Rio de Janeiro. Rio de Janeiro, p. 416. 2015. 


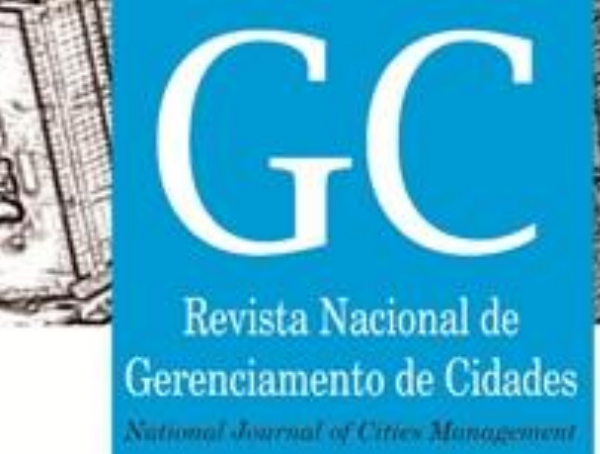

ROCHA, R. T.; LELES, S. S.; NETO, S. N. O. Arborização de vias públicas em Nova Iguaçu, RJ: o caso dos bairros de Rancho Novo e Centro. Revista árvore, Viçosa, p. 599-607, 2004.

ROSSETTI, A. I. N. A arborização na qualificação do espaço da rua: uma proposta metodológica de inventário, manejo e planejamento de verde viário em dois bairros paulistanos. Faculdade de Arquitetura e UrbanismoUniversidade de São Paulo. São Paulo, p. 208. 2007.

SALVI, L. T. et al. Arborização ao longo de Ruas- Túneis verdes- Em Porto Alegre, RS, Brasil: Avaliação quantitativa e qualitativa. Revista Árvore, Viçosa, v. 35, n. 2, p. 233-243, 2011.

SANTOS, C. Z. A. et al. Análise qualitatuva da arborização urbana de 25 vias públicas da cidade de Aracaju-SE. Ciência Florestal, Santa Maria, v. 25, n. 3, p. 751-763, jul-set 2015.

SANTOS, P. J. F. A percepção dos moradores sobre a arborização de Rondonópolis. Universidade Federal do Mato Grosso-UFTM. [S.I.]. 1997.

SECRETARIA DO MEIO AMBIENTE E SUSTENTABILIDADE DE RECIFE. Manual de arborização urbana de Recife. Recife. 2013.

SILVA FILHO, D. F.; COSTA, F. P. S.; POLIZEL, J. Planejamento da arborização urbana da cidade de Enegnheiro CoelhoSP: Uso de SIG e de inventário Amostral. Revista Geografia em Atos, Presidente Prudente, v. 1, n. 12, p. 1-18, 2012.

SILVA FILHO, F. S. et al. Banco de dados relacional para cadastro, avaliação e manejo da arborização em vias públicas. Revista árvore, Viçosa-MG, n. 26, p. 629-642, 2002.

SILVA, L. F. et al. Arborização viária urbana: espécies de pequeno porte com potencial de uso. Revista Brasileira Horticultura Ornamental, Campinas, v. 11, n. 1, p. 13-20, 2005.

SILVA, M. P. Método de avaliação da qualidade espacial e estético-ambiental da arborização viária. Universidade Estadual Paulista "Júlio de Mesquita Filho". Bauru, p. 89. 2018.

SILVA, R. N. Caracterização e Análise Quali-Quantitativa da arborização em praças da área central da cidade de Arapiraca, AL. Revsbau, Piracicaba-SP, v. 7, n. 2, p. 102-115, 2012.

SITTE, C. A construção das cidades segundo seus princípios artísticos. 1o. ed. São Paulo: Ed. Ática, 1992. 239 p.

SOUZA, H. M. D. Arborização de ruas. Secretaria da Agricultura, Instituto Agronômico. São Paulo. 1973.

VIGNOLA JÚNIOR, R. ArbVias- Método de avaliação da arborização no sistema viário Urbano. Paisagem e Ambiente, São Paulo, n. 35, p. 89-117, 2015. 